\title{
Anti- tuberculosis activities of medicinal plants used in the treatment of tuberculosis in HIV patients in Nigeria
}

\author{
Anochie, P. I. ${ }^{1}$, Onyejepu, N. ${ }^{1}$, Ogu A. C. ${ }^{2}$, Adetunji, M. A. ${ }^{1}$, Efere, L. $0 .{ }^{1}$, Onyeozirila, A. C. ${ }^{3}$, \\ Onyeneke, E. C. ${ }^{4}$, Onyeneke, C. N. ${ }^{5}$, Obinna, J. U. ${ }^{6}$, Srikanth, A. ${ }^{7}$ and Bueno, J. ${ }^{8}$ \\ ${ }^{1}$ Nigerian Institute of Medical Research, Yaba, Lagos, Nigeria. \\ ${ }^{2}$ Department of Medicine, University of Sheffield, UK. \\ ${ }^{3}$ Department of Medicine, Madonna University, Elele, Rivers State, Nigeria. \\ ${ }^{4}$ Federal Medical Center, Owerri, Imo State, Nigeria. \\ ${ }^{5}$ Department of Microbiology, Abia State University, Abia State, Nigeria. \\ ${ }^{6}$ Ogun State University Teaching Hospital, Ogun State, Nigeria. \\ 'School of Biosciences Technology, VIT University, India. \\ ${ }^{8}$ Grupo de Micobacterias, Instituto Nacional de Salud, Bogota, D.C, Colombia.
}

Accepted 19 April, 2011

\begin{abstract}
Local herbalists in Nigeria claimed that extracts of certain parts, that is, stem and seeds obtained from Crinum glaucum,Treculia africana, Erythrina mildbaedi, Ficus thonningii and Xylopis aethiopica are used to treat tuberculosis patients. We conducted a laboratory-based study of this claim scientifically using the procedures employed by the local herbalists. The Mycobacterium tuberculosis strain used in this study was obtained locally and characterized based on cultural and biochemical tests on isolates of bacteriologically proven tuberculosis positive patients. The $M$. tuberculosis strains were found resistant to all the extracts. There was no growth on the isoniazid drug containing medium which was used as control. There was growth on all the LJ medium containing the extracts. The results of these findings shows that the extracts of these plants exhibited no significant anti-microbial activity against M. tuberculosis and therefore not recommendable for clinical use as an anti-tuberculosis drug.
\end{abstract}

Key words: Anti-tuberculosis, activity, medicinal plants, treatment, HIV patients, Nigeria.

\section{INTRODUCTION}

A number of antimicrobial agents already exist for various purposes but the search for new antimicrobial agents should be a continous one since the target microorganisms often evolve into new genetic variants which subsequently become resistant to existing agents. Many higher plants are known to produce antimicrobial agents (Sakuma and Tomiyana, 1967), and indeed extracts of plants from different parts of the world have been shown to possess antimicrobial properties (Malcom and Sofowora, 1969; Bhakuni and Bittner, 1974; BoakyeYiadom, 1977).

With the current trend in the biotechnology of plant tissue culture (Curtin, 1983), it would appear that man may soon have to depend on plants as a source of a

${ }^{{ }^{*} C o r r e s p o n d i n g ~ a u t h o r . ~ E-m a i l: ~ i p . a n o c h i e @ n i m r . g o v . n g ~ o r ~}$ philipanochie@yahoo.co.uk. number of antimicrobial agents since these plants will most likely continue to produce antimicrobial agents which could be used against infections by microorganisms.

However, the local herbalists that use these plants for medicinal use did not do a scientific study of the aethiologic agents in these herbs before using on patients and as such, a laboratory screening of these herbs need to be carried out, hence the need for this study to determine and evaluate the anti-tuberculosis effects of Crinum glaucum, Treculia africana, Erythrina mildbaedi, Ficus thonningii, and Xylopis aethiopica which are medicinal plants used by local herbalists in Nigeria for the treatment of tuberculosis (TB ) in Human Immun Deficiency Virus (HIV) -infected patients.

This study is to determine the potency of these medicinal plants against Mycobacterium tuberculosis which will help to develop new drugs against the infection from these local plants extracts which will in turn 
conserve foreign exchange through local development of drugs. The study will also ensure that the use of these medicinal plants in traditional folk medicine is based on informed scientific appraisal.

\section{MATERIALS AND METHODS}

The plant materials were purchased from local markets in Nigeria and identified by the Department of Botany, University of Lagos, Department of Pharmacognosy, College of Medicine, University of Lagos, and the Department of Botany, Abia State University, Nigeria.

\section{Extraction}

Stems of C. glaucum, E. mildbaedi, $F$. thonningii, seeds of $T$. africana, and $X$. aethiopica were cut to very small pieces and crushed into powder using a warring blender. Aqueous and ethanol extracts were obtained using soxhlet apparatus and later filtered using Whatman filter paper No. 1(Whatman, UK) and membrane filter (Millipore, France). The filterates were freeze dried in a lyophilizer.

Residues obtained were stored in sterile universal containers and refrigerated at $4{ }^{\circ} \mathrm{C}$ prior to use. The plants used for this study resulted into two groups of extracts which are the aqueous (water) extracts, in which water was used as the solvent (WEwater+ethanol) and the ethanol (Alcohol) extracts (EE = ethanol + extract) in which $70 \%$ ethanol was used as the solvent. The two groups of extracts were labeled accordingly, stored in a refrigerator and later incorporated into Loweinstein-Jensen (LJ) medium.

\section{Incorporation of the isoniazid drug and the extracts into Loweinstein-Jensen (LJ) medium}

The control drug used for this study isoniazid. The susceptibility test was carried out by the proportion method using plain LJ medium without drug, extract or organism and another with organism and no drug or extract, LJ medium with isoniazid drug and LJ medium with $M$.tuberculosis reference strain H37RV (American type culture collections: ATCC 27294) as controls. The isoniazid and the extracts were incorporated separately into the LJ medium before inspissation. The incorporation of the isoniazide, and the extracts into the LJ slopes, and the inoculation of the local and reference strains of the $M$. tuberculosis as well as the assessment of the antituberculosis activities of the extracts were performed using standard procedures (Hans et al., 1998; Canetti et al., 1969).

The two groups of extracts (WE and EE) were prepared in different concentrations of $0.1,0.2,0.3,0.4$ up to $500 \mathrm{mg} / \mathrm{ml}$, labeled accordingly and stored in a refrigerator. A quantity of 20.0 $\mathrm{mg}$ of the drug or extract was dissolved in $40.0 \mathrm{ml}$ of sterile distilled water to make a $500 \mu \mathrm{g} / \mathrm{ml}$ solution. $2.0 \mathrm{ml}$ of this solution was diluted aseptically using a $50.0 \mathrm{ml}$ volumetric flask to make a 20.0 $\mu \mathrm{g} / \mathrm{ml}$ stock solution or $0.2 \mu \mathrm{g} / \mathrm{ml}$ critical drug concentrations. This was sterilized by membrane filtration using a membrane filter (Millipore, France) of pore size 0.25 microns.

Then $10.0 \mathrm{ml}$ of filtered $20.0 \mu \mathrm{g} / \mathrm{ml}$ drug or extract solution is added aseptically to $1000 \mathrm{ml}$ of sterile LJ medium. This was shaken gently to mix thoroughly. Then $7 \mathrm{ml}$ of the medium was dispensed into 17 by $170 \mathrm{~mm}$ sterile universal containers and then inspissated to coagulate at $85^{\circ} \mathrm{C}$ for 45 mins. The LJ slopes were left at room temperature for $24 \mathrm{~h}$, the caps on the universal containers being loosely closed in order to evaporate a part of the humidity. (Canetti et al., 1969). The universal containers were then closed, stored and refrigerated at $4{ }^{\circ} \mathrm{C}$. The control medium without extract or drug was prepared at the same time as the extract or drug containing media. The reference strain, M. tuberculosis H37RV(ATCC 27294) which is susceptible to all primary and secondary anti-tuberculosis drugs was used as control strain (Sakuma and Tomiyana, 1967).

Aliquots of suspension of control strain of $M$. tuberculosis and local isolates being studied were adjusted to match a Mcfarland 1 standard and stored at $-70^{\circ} \mathrm{C}$ refrigerator. The LJ media and the antimicrobial agents were checked for sterility (Malcom and Sofowora, 1969). The extracts were subjected to the same procedure as the control drug according to the drug preparation procedure for proportion method of drug susceptibility testing (Hans et al., 1998).

\section{Inoculation of the organism}

With a sterilized spatula, a representative sample of $10 \mathrm{mg}$ was taken from the primary culture. This mixture of the majority of the colonies were collected and placed in a spherical, flat-bottomed flask containing 12 glass beads of $3 \mathrm{~mm}$ in diameter. The flask was shaken for $30 \mathrm{~s}$. Then $5 \mathrm{ml}$ of sterile distilled water was added slowly under continous shaking. The opacity of the bacterial suspension was then adjusted by the addition of sterile distilled water to that of a standard suspension containing $1 \mathrm{mg} / \mathrm{ml}$ of tubercle bacilli (or BCG/ McFarland 1 standard) 7. The inoculation of the LJ slopes were performed using sterile calibrated loops and pipettes.

The loop was made of platinum wire of diameter $0.7 \mathrm{~mm}$ and have an internal diameter of $3 \mathrm{~mm}$. The two bacterial dilutions used for inoculation with the loop are $10^{-2}$ and $10^{-4} \mathrm{mg} / \mathrm{ml}$. The two inocular were respectively $10^{-4}$ and $10^{-6} \mathrm{mg}$ of bacilli for each slope. The dilution of $10^{-2} \mathrm{mg} / \mathrm{ml}$ was produced by discharging two loopfuls of the bacterial suspension standardized at $1 \mathrm{mg} / \mathrm{ml}$ into a small tube containing $2 \mathrm{ml}$ of sterile distilled water.

Similarly, the dilution $10^{-4} \mathrm{mg} / \mathrm{ml}$ was produced by discharging two loopfuls of the $10^{-2} \mathrm{mg} / \mathrm{ml}$ into a small tube containing $2 \mathrm{ml}$ of sterile distilled water and shaking. Two slopes of medium without drug or extract and two slopes of medium with drug and extract were inoculated with a loopful of each dilution. Using a pipette, the inoculum for each slope was $0.1 \mathrm{ml}$. Accordingly, the two bacterial dilutions used for inoculation with the pipette were $10^{-3}$ and $10^{-5}$ $\mathrm{mg} / \mathrm{ml}$.

The dilutions were prepared by 10 -fold dilution steps $(0.5 \mathrm{ml}$ of the bacterial suspension $1 \mathrm{mg} / \mathrm{ml}$, discharged into $4.5 \mathrm{ml}$ of distilled water, produces the dilution $10^{-1} \mathrm{mg} / \mathrm{ml}, 0.5 \mathrm{ml}$ of the bacterial suspension $10^{-1} \mathrm{mg} / \mathrm{ml}$, discharged into $4.5 \mathrm{ml}$ of distilled water, produces the dilution $10^{-1} \mathrm{mg} / \mathrm{ml}$ and so on, down to $10^{-5} \mathrm{mg} / \mathrm{ml}$ ). The pipette was changed for each dilution. Two slopes of medium without extract or drug and two slopes of medium with drug or extracts were inoculated with $0.1 \mathrm{ml}$ of the two chosen dilutions of $10^{-3}$ and $10^{-5} \mathrm{mg} / \mathrm{ml}$.

The inoculated slopes were loosely closed with a cap just placed on them. The slopes were put in a stand at a very slight angle from the horizontal and placed in the incubator at $37^{\circ} \mathrm{C}$. The liquid covered as much surface of the medium as possible, without touching the cap. When the liquid part of the inoculum evaporated at $30 \mathrm{~h}$, the slopes were firmly closed with caps and kept in the incubator at $37^{\circ} \mathrm{C}$.

\section{RESULTS}

The results were read for the first time on the 28th day. 
The colonies were counted only on the slopes seeded with the lowest inoculum that has produced growth. The inoculum was the same as the control slopes and extract containing slopes with low inoculum $\left(10^{-5} \mathrm{mg}\right.$ of bacilli) for the control slopes and high inoculum $\left(10^{-3} \mathrm{mg}\right.$ of bacilli) for the extract containing slopes. The average number of colonies obtained $(\mathrm{cfu} / \mathrm{ml})$ for the two control slopes indicated the number of culturable particles contained in the inoculum. The average number of colonies obtained for the extract containing slopes indicated the number of resistant bacilli contained in the inoculum.

The ratio between the second figure and the first indicates the proportion of resistant bacilli existing in the strain. Below a certain proportion (the critical proportion) the strain was classified as sensitive, above it was classified as resistant. The proportions are reported in terms of percentages. According to the criteria for resistance which indicated that any strain showing a proportion of resistant bacilli equal or superior to that indicated is classified as resistant to the corresponding drug or extract. The drug concentration of isoniazide is $0.2 \mu \mathrm{g} / \mathrm{ml}$ and the critical proportion for resistant percentage is $1 \%$ (Canetti et al., 1969).

The result of the reading made on the 28th day was "resistant". Had it been that it was "sensitive" on the 28th day, a second reading would have been made on the 42 nd day which will provide the definite result. For the calculation of the proportion of resistant bacilli, the highest count obtained on the extract free or drug free medium and on the drug or extract containing medium was taken regardless of whether this count was obtained on the 28th day, on the 42nd day or on the 28th day with one medium and on the 42nd day with the other. The number of colonies on the control and extract containing media were counted. Since the critical proportion for resistance expressed in percentages for isoniazide is $1 \%$, this was taken and used for the control drug (isoniazide) and also for the extracts.

Any isolate that showed more than $1 \%$ bacteria population growing on the extract containing medium as compared to the control medium without extract or drug was considered as resistant (Inderlied, 1991). Bearing in mind that isoniazide used as the control drug has a critical proportion for resistance percentage of $1 \%$, the percentage bacterial population for each extract or drug proportion for resistance (\%) was calculated using the formulae:

$=$ Number of colonies from control slopes with low inoculums $\left(10^{-5}\right)$ divided by number of colonies from drug slopes with high inoculum $\left(10^{-3}\right)$.

= Number of colonies from control slopes with high inoculums $\left(10^{-3}\right)$ divided by number of colonies from drug slopes with low inoculums $\left(10^{-5}\right)$.

Therefore; for (A) control slopes with low inoculum divided by drug slopes with high inoculum $=$ Control $10^{-5} /$
Drug $10^{-3}$

Therefore, $A=$ Control $10^{-5} /$ Drug $10^{-3}$

(Control drug has no drug or extract)

For $(\mathrm{B})=$ Control $10^{-3} /$ Drug $10^{-5}$

$A: B \times \%=C$

When $\mathrm{C}=<1 \%=$ sensitive

When $\mathrm{C}=\geq 1 \%$ = resistant

(Critical proportion for resistance for isoniazide $=1 \%$ )

(1) Applying the formulae to the isoniazide control slope: Number of colonies on control slope $10^{-5}=>100$ colonies. Number of colonies on isoniazide control slope $10^{-3}=0$ colonies.

Number of colonies on control slopes $10^{-3}=>100$ colonies.

Number of colonies on isoniazide control slope $10^{-5}=0$ colonies.

Applying the formulae $\mathrm{A}: \mathrm{B} X \%=\mathrm{C}$

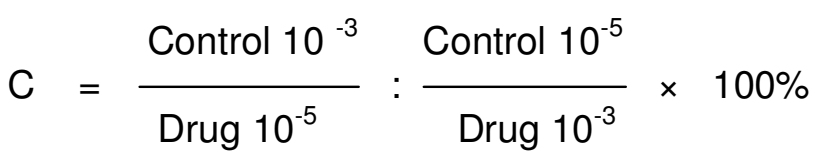

$\frac{100}{0}: \frac{100}{0} \times 100 \%=0$

$0=<1=$ sensitive.

The colonies are sensitive to isoniazide.

(2) Applying this formulae to the extract WE1:

Number of colonies on control slope $10^{-5}=>100$ colonies . Number of colonies on WE1 extract $10^{-3}=>100$ colonies. Number of colonies on control slope $10^{-3}=>100$ colonies. Number of colonies on WE1 slope $10^{-5}=>100$ colonies.

$$
\begin{array}{ll}
A=\frac{\text { Control } 10^{-5}}{\text { Extract WE1 } 10^{-3}}=\frac{>100}{>100} \\
B=\frac{\text { Control } 10^{-3}}{\text { Extract } 10^{-5}} \quad=\frac{>100}{>100}
\end{array}
$$

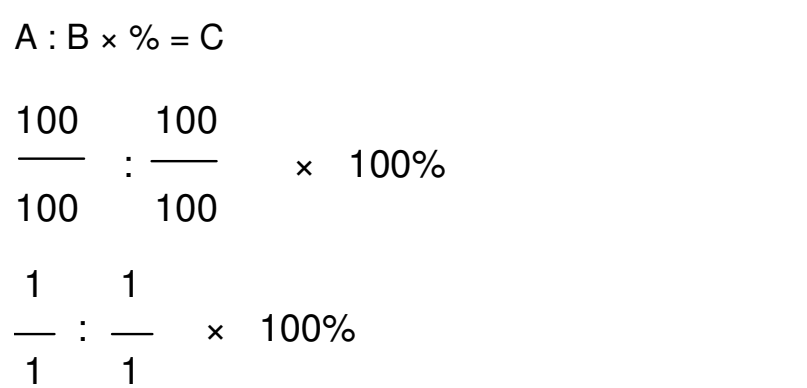


Table 1. Assessment of the anti-tuberculosis activities of the extracts.

\begin{tabular}{|c|c|c|c|c|c|}
\hline $\mathbf{S} / \mathbf{n}$ & Growth medium (drug/extracts) & $\begin{array}{l}\text { Inoculum } \\
\text { dilution } \\
(\mathrm{mg} / \mathrm{ml})\end{array}$ & $\begin{array}{c}\text { Number of } \\
\text { colonies } \\
\text { Obtained }(\mathrm{cfu} / \mathrm{ml})\end{array}$ & $\begin{array}{c}\text { Percentage } \\
\text { Bacterial } \\
\text { population (\%) }\end{array}$ & Result \\
\hline 1. & Isoniazid control & $10^{-3}$ & 0 & 0 & + \\
\hline 2. & Isoniazid control & $10-^{5}$ & 0 & 0 & + \\
\hline 3. & LJ medium with inoculums (control) & $10^{-3}$ & $>100$ & 1 & - \\
\hline 4. & LJ medium with inoculums (control) & $10^{-5}$ & $>100$ & 1 & - \\
\hline 5. & WE1 & $10^{-3}$ & $>100$ & 1 & - \\
\hline 6. & WE1 & $10^{-5}$ & $>100$ & 1 & - \\
\hline 7. & EE1 & $10^{-3}$ & $>100$ & 1 & - \\
\hline 8. & EE1 & $10^{-5}$ & $>100$ & 1 & - \\
\hline 9. & WE2 & $10^{-3}$ & $>100$ & 1 & - \\
\hline $10 .$. & WE2 & $10^{-5}$ & $>100$ & 1 & - \\
\hline 11. & EE2 & $10^{-3}$ & $>100$ & 1 & - \\
\hline 12. & EE2 & $10^{-5}$ & $>100$ & 1 & - \\
\hline 13 & WE3 & $10^{-3}$ & $>100$ & 1 & - \\
\hline 14. & WE3 & $10^{-5}$ & $>100$ & 1 & - \\
\hline 15. & EE3 & $10^{-3}$ & $>100$ & 1 & - \\
\hline 16. & EE3 & $10^{-5}$ & $>100$ & 1 & - \\
\hline 17. & WE4 & $10^{-3}$ & $>100$ & 1 & - \\
\hline 18. & WE4 & $10^{-5}$ & $>100$ & 1 & - \\
\hline 19. & EE4 & $10^{-3}$ & $>100$ & 1 & - \\
\hline 20. & EE4 & $10^{-5}$ & $>100$ & 1 & - \\
\hline 21. & WE5 & $10^{-3}$ & $>100$ & 1 & - \\
\hline 22. & WE5 & $10^{-5}$ & $>100$ & 1 & - \\
\hline 23. & EE5 & $10^{-3}$ & $>100$ & 1 & - \\
\hline 24. & EE5 & $10^{-5}$ & $>100$ & 1 & - \\
\hline
\end{tabular}

The same results were obtained at $10^{-2} \mathrm{mg} / \mathrm{ml}$ and $10^{-4} \mathrm{mg} / \mathrm{ml}$ dilutions.

Key: + M. tuberculosis sensitive to extract/drug, - M. tuberculosis resistant to extract /drug. WE1 = Water extract Crinum glaucum, EE1 = Ethanol extract Crinum glaucum, WE2 $=$ Water extract Treculia Africana, EE2 $=$ Ethanol extract Treculia Africana, WE3 $=$ Water extract Erythrina mildbaedi, EE3 = Ethanol extract Erythrina mildbaedi, WE4 = Water extract Ficus thonningii, EE4 = Ethanol extract Ficus thonningii, WE5 = Water extract Xylopis aethiopica, EE5 = Ethanol extract Xylopis aethiopica.

$=1 \times 100 \%=1 \%=$ Resistant

(The colonies were resistant to extract WE1). The same method and formular was also used for the calculation and determination of the susceptibility of the other extracts and the results are shown in Table 1. The overall result shows that the extracts has no anti-tuberculosis effect and that the colonies of the $M$. tuberculosis are highly resistant to the extracts hence the uninhibited growth of the extract-containing medium. This result was confirmed by ZN staining, microscopy and biochemical tests to be M. tuberculosis.

\section{DISCUSSION}

The resistance shown by the organism on the extracts means that the extracts were not able to inhibit the $M$. tuberculosis strains. Extracts from these herbs are therefore not recommendable for clinical use as an antituberculosis drug until further work has been done in them like in other herbs. Patients that take these extracts as a way of treatment of TB may be doing so out of ignorance of the availability of better treatment or they could not afford the long treatment period of two to eight months needed to treat TB for proper cure or they cannot afford the money to buy the drugs that they will use for that long period but with the advent of the directly observed therapy short course (DOTS) programme which provides free diagnosis and treatment of TB (recognized as efficient by the World Health Organisation (WHO), if these patients are aware of this, it will be helpful to them. For those that are aware of the programme, treatment failures can mislead them into taking these extracts as a curative measure.

Most of the herbal practitioners claim that their herbal extracts can cure a lot of diseases including TB. The result of this study has proved otherwise. Most of the 
patients they claim to have treated were not subjected to X-ray or laboratory investigations to prove their case. They may be suffering from other respiratory infections. It is only when more work has been done like in other herbs that this claim may be valid. Laboratory studies should be carried out on other herbs that are used by local traditional healers for the treatment of various infections. The disease which the local herbalist 'cure' or manage with the herbs used in this study could even be pneumonia, ordinary cough or could even be due to any other opportunistic respiratory tract infection other than M. tuberculosis .

\section{ACKNOWLEDGEMENT}

The authors would like to thank some members of staff of the Nigerian Institute of Medical Research, Federal Medical Center, Owerri, Imo state, Nigeria, Abia State, Nigeria, and the University of Sheffield Department of Medicine, UK, for their immeasurable support and luxuries forgone to make this project a reality.

\section{REFERENCES}

Bhakuni DS, Bittner M, Bittner M, Marticorena C, Silva M, Weidt E (1974). Screening of Chilean plants for antimicrobial activity. Lloydia, 37: $621-632$.

Boakye-Yiadom K (1977). Antimicrobial properties of some West African plants. Antimicrobial action of Bryophylum pinnatum. Lam. Quart. J. Crude Drug Res., 15: 201-202.
Canetti G, Fox W, Khomenko A, Mahler HT, Melon NK, Mitchison DA, Rist N, Smelec NA (1969). Advances in techniques for testing mycobacterial drug sensitivity and the use of sensitivity tests in tuberculosis control programs. Bull. Wld. Health Org., 41: 21-43.

Curtin ME (1983). Harvesting profitable products from plant tissue culture. Biotechnology, 1: 649-657.

Hans LR, Martin TC, Helge M, Richard U, Adalbert L, Sang JK, Armand VD, Arnauld T (1998). The Public Health Service, National Tuberculosis Reference Laboratory and the National Laboratory Network. Minimum requirement, role and operation in a low income country. IUATLD, pp. 72-82.

Inderlied CB (1991). Antimycobacterial agent : In vitro susceptibility testing, spectrums of activity, mechanisms of action and resistance, and assays for activity in biological fluids. In V. Loriane. The Williams and Wilkins Co. Baltimore, U.S.A., pp. 134-197.

Inderlied C, Salfinger B (1993). Antimicrobial agents and susceptibility tests; Mycobacteria. Clinical Microbiology manual, American Association for Microbiology (ASM) $5^{\text {th }}$ edition, pp. 1385-1396.

Malcom SA, Sofowora EA (1969). Antimicrobial activity; Selected Nigerian folk remedies and their constituent plants. Lloydia, 32: 512.

Sakuma T, Tomiyana K (1967). The role of phenolic compounds in the resistance of potato tuber tissue infection by Phytophtora infectans. Ann. Phyto. Pathol. Soc. Jpn., 33: 48-58. 